\title{
Head \& neck acinar cell carcinoma: a population-based study using the seer registry
}

Feiluore Yibulayin ${ }^{1,2}$, Lei Feng ${ }^{1}$, Meng Wang ${ }^{1}$, Meng-meng Lu'1 Yuan Luo', Hui Liu', Zhi-cheng Yang ${ }^{1 *}$ and Alimujiang Wushou ${ }^{1 *}$ (D)

\begin{abstract}
Background: To explore the clinicopathologic characteristics, treatment and prognostic factors of head and neck acinar cell carcinoma (HNACC) comprehensively.

Methods: A population-based study was conducted using data from the Surveillance, Epidemiology, and End Results database (1975-2016). Overall survival (OS) and HNACC-specific survival of patients with different clinicopathologic variables were compared using the Kaplan-Meier method and Cox multivariate regression.

Results: A total of 2624 primary HNACC cases (1052 males, 1572 females) were identified. There was a significant difference in gender distribution. Among the total cohort, 2416 cases originated from salivary glands, including 2325 parotid gland ACC cases. Regardless of confounding factors, the 10-year and 20-year disease-specific survival (DSS) was 93.6 and 90\%, respectively. Surgery was favourably associated with better DSS and OS [HR $=0.13, P=$ 0.0092 and $H R=0.23, P=0.0203]$. Gender was the only demographic independent prognostic factor for both DSS and OS [Male vs female, HR=3.3, $P=0.0028$ for DSS; HR $=2.44, P=0.0376$ for OS]. Higher pathological grade was adversely associated with DSS and OS [Grade II, HR=4.03, $P=0.0444$; Grade III + IV, HR $=35.64, P=0.0000$ for DSS; Grade III + IV, HR=4.49, $P=0.0000$ for OS, Grade I as reference]. In addition, TNM/AJCC stage was commonly associated with prognosis.
\end{abstract}

Conclusion: Surgery was the only favourable prognostic indicator for both DSS and OS. Gender, age, pathological differentiation and TNM/AJCC stage were independent prognostic factors for survival.

Keywords: Acinar cell carcinoma, Head and neck, Survival, Prognostic factor, SEER database

\section{Background}

Salivary gland malignant tumours account for $1-3 \%$ of head and neck cancers [1]. Acinar cell carcinoma (ACC) is an uncommon malignant tumour, and its predominant site of origin is salivary glands in the head and neck region [2]. Approximately $80 \%$ of ACC originates in the parotid

\footnotetext{
* Correspondence: Zhicheng_yang1998@Fufudan.edu.cn;

Wushoua@fudan.edu.cn

'Department of Oral \& Maxillofacial Surgery and Oral Biomedical Engineering Laboratory Shanghai Stomatological Hospital, Fudan University, 356 Beijing East Road, Shanghai 200001, People's Republic of China

Full list of author information is available at the end of the article
}

gland; the remaining disease originates in the submandibular and sublingual glands, and there are reports involving the hypopharynx, lip, thyroid, tongue and tonsil [3]. Head and neck ACC (HNACC) is mainly found in the salivary gland, and ACC accounts for only approximately $6 \%$ of all salivary gland neoplasms. Apart from mucoepidermoid carcinoma, adenocarcinoma, and adenoid cystic carcinoma, ACC is the fourth most common reported malignancy of the parotid gland. Given the rarity of the disease, data on the general demographics, clinical

C C The Author(s). 2020 Open Access This article is licensed under a Creative Commons Attribution 4.0 International License, which permits use, sharing, adaptation, distribution and reproduction in any medium or format, as long as you give appropriate credit to the original author(s) and the source, provide a link to the Creative Commons licence, and indicate if changes were made. The images or other third party material in this article are included in the article's Creative Commons licence, unless indicated otherwise in a credit line to the material. If material is not included in the article's Creative Commons licence and your intended use is not permitted by statutory regulation or exceeds the permitted use, you will need to obtain permission directly from the copyright holder. To view a copy of this licence, visit http://creativecommons.org/licenses/by/4.0/ The Creative Commons Public Domain Dedication waiver (http://creativecommons.org/publicdomain/zero/1.0/) applies to the data made available in this article, unless otherwise stated in a credit line to the data. 
characteristics, treatment and prognosis of HNACC are still sporadic [4].

There have been no controlled studies that define the optimal treatment for HNACC. The treatment modalities reported including surgical resection, radiotherapy and chemotherapy, and combined therapies with variable results [3]. However, among all salivary gland cancers, HNACC has a relatively favourable prognosis [5]. It is worth noting that, based on some researchers' institutional experience, HNACC is classified as a low-grade cancer regardless of its clinicopathologic features [6]. Pathological differentiation (high grade vs low grade) is the only considered prognostic indicator [7]. ACC has a tendency to recur locoregionally, to produce lymph node and distant metastasis, and to display aggressive evolution [8].

For rare tumours, nationwide population-based retrospective analysis may make it possible to evaluate trends in demographic features, clinicopathologic characteristics, treatment modalities and disease-specific prognostic indicators. We conducted a comprehensive analysis of all primary HNACC cases registered in the Surveillance, Epidemiology, and End Results (SEER) database of the United States National Cancer Institute from 1975 to 2016.

\section{Methods}

\section{Study population}

SEER*Stat software developed by the National Cancer Institute (Surveillance Research Program, National Cancer Institute SEER*Stat software 8.3.6; https://seer.cancer.gov) was used to extract the study cases. International Classification of Diseases for Oncology (ICD-O-3) codes for acinar cell carcinoma (8550/3) and head and neck topographic codes were used to identify cases with a diagnosis of HNACC registered in the SEER database. The variables in the analysis included marital status at diagnosis, insurance status, tumour orientation, age range, mean age, gender, race, pathological differentiation, American Joint Committee on Cancer (AJCC) stage, TNM stage, neck dissection, surgery, radiotherapy and chemotherapy. Our study used established data and did not involve interaction with human subjects. Therefore, institutional review board approval was not required.

\section{Statistical analysis}

Statistical analysis was performed using the statistical packages R (The R foundation; http://www.r-project.org; version 3.4.3), Empower R (http://www.empowerstats. com, Boston, Massachusetts), and the Statistical Package for the Social Sciences, Version 23.0, for Windows (SPSS, Chicago, IL). Differences in numerical variables were assessed using Student's t-test or the nonparametric Wilcoxon test. The chi square test or Fisher's exact test for categorical variables was used for twogroup comparisons of parameters. Survival curves for different variable values were generated using KaplanMeier estimates and were compared using the log-rank test. Variables that achieved significance at $P<0.05$ were entered into the multivariable analyses via the Cox regression model.

\section{Results}

\section{Summary statistics}

A total of 2624 primary HNACC cases were included in the study. The demographic and clinicopathological characteristics of the cases are summarized in Table 1. There is a significant difference in gender distribution; 1052 of the cases are male, and 1572 are female. The mean age at diagnosis was 50 years for the total cohort and ranged from 5 to 96 years. According to this dataset, HNACC occurred in the lip, nose and nasal cavity, middle ear, eye and orbit, gum, floor of the mouth, tonsil, tongue, thyroid gland, oropharynx, nasopharynx, hypopharynx, larynx, pharynx, submandibular gland, sublingual gland and parotid gland. Among the total cohort, 2416 cases originated from salivary glands, including 2325 parotid gland ACC cases. White people accounted for $81 \%$ of the total population $(2131 / 2624)$. With respect to pathological differentiation, definite pathological information was available for only 938 cases. Most of the cases were grade I and grade II; grade III plus IV carcinoma accounted for $12.3 \%$. The percentages of cases with lymph node metastasis and distant metastasis were 7\% (96/1351) and 6\% (76/1183), respectively. Surgical resection was the primary treatment modality. Surgery was performed in 2516 patients, including 905 patients in which simultaneous neck dissection was performed, and 839 cases received surgery plus radiotherapy.

\section{Survival analysis}

Kaplan-Meier analysis was performed for time-to-event analysis for overall survival (OS) and disease-specific survival (DSS). Regardless of confounding factors, 5-year, 10year and 20-year OS was 90, 80 and 64\%, respectively. Significant differences in OS were found depending on age range $(P<0.0001)$, mean age $(P<0.0001)$, marital status at diagnosis $(P<0.0001)$, gender $(P=0.01)$, pathological differentiation $(P<0.0001)$, race $(P=0.007)$, AJCC stage $(P<0.0001)$, AJCC T stage $(P<0.0001)$, AJCC N stage $(P<0.0001)$, AJCC $\mathrm{M}$ stage $(P<0.0001)$, surgery, $(P<$ $0.0001)$, radiotherapy $(P<0.0001)$, chemotherapy $(P<$ $0.0001)$ and combined treatment modality $(P<0.0001)$ (Fig. 1). Of the total cohort, 2203 patients were available for DSS analysis. The median follow-up time for these cases was 123 months (range, 1-503 months). Regardless of all other factors, 10-year and 20-year DSS was 93.6 and $90 \%$, respectively, for patients who received surgery alone 
Table 1 The summary of HNACC patients' clinicopathologic characteristics

\begin{tabular}{|c|c|c|c|c|c|c|c|c|c|}
\hline \multirow[t]{2}{*}{ Variables } & & \multicolumn{4}{|c|}{ Disease specific survival } & \multicolumn{4}{|c|}{ Overall survival } \\
\hline & & Alive & Dead & Total & $P$-value & Alive & Dead & Total & $P$-value \\
\hline \multirow[t]{3}{*}{ Marital status at diagnosis } & Single & 568 & 28 & 596 & 0.000 & 569 & 69 & 638 & 0.000 \\
\hline & Married & 1086 & 129 & 1215 & & 1094 & 355 & 1449 & \\
\hline & Other status & 204 & 56 & 260 & & 204 & 175 & 379 & \\
\hline \multirow[t]{3}{*}{ Insurance status } & Any Medicaid & 94 & 8 & 102 & 0.224 & 94 & 12 & 106 & 0.837 \\
\hline & Insured & 866 & 44 & 910 & & 873 & 78 & 951 & \\
\hline & Uninsured & 28 & 3 & 31 & & 28 & 5 & 33 & \\
\hline \multirow[t]{2}{*}{ Tumor orientation } & Salivary gland & 1845 & 210 & 2055 & 0.175 & 1854 & 562 & 2416 & 0.002 \\
\hline & Beyond salivary gland & 138 & 10 & 148 & & 140 & 68 & 208 & \\
\hline \multirow[t]{8}{*}{ Age age } & 0-19 & 171 & 0 & 171 & 0.000 & 171 & 3 & 174 & 0.000 \\
\hline & $20-29$ & 243 & 5 & 248 & & 243 & 10 & 253 & \\
\hline & $30-39$ & 323 & 15 & 338 & & 324 & 34 & 358 & \\
\hline & $40-49$ & 398 & 32 & 430 & & 399 & 66 & 465 & \\
\hline & $50-59$ & 396 & 41 & 437 & & 398 & 103 & 501 & \\
\hline & $60-69$ & 288 & 58 & 346 & & 291 & 152 & 443 & \\
\hline & $70-79$ & 119 & 36 & 155 & & 122 & 163 & 285 & \\
\hline & $80+$ & 45 & 33 & 78 & & 46 & 99 & 145 & \\
\hline \multirow[t]{2}{*}{ Gender } & Female & 1210 & 112 & 1322 & 0.004 & 1219 & 353 & 1572 & 0.000 \\
\hline & Male & 773 & 108 & 881 & & 775 & 630 & 1405 & \\
\hline \multirow[t]{3}{*}{ Race } & Black & 193 & 16 & 209 & 0.003 & 193 & 45 & 238 & 0.000 \\
\hline & White & 1570 & 196 & 1766 & & 1579 & 552 & 2131 & \\
\hline & Others & 179 & 7 & 186 & & 181 & 30 & 211 & \\
\hline \multirow[t]{3}{*}{ Pathological grade } & Grade I & 407 & 18 & 425 & 0.000 & 409 & 71 & 480 & 0.000 \\
\hline & Grade II & 283 & 20 & 303 & & 284 & 59 & 343 & \\
\hline & Grade III + IV & 42 & 56 & 98 & & 42 & 73 & 115 & \\
\hline \multirow[t]{3}{*}{ AJCC stage } & Stage I & 531 & 8 & 539 & 0.000 & 532 & 35 & 567 & 0.000 \\
\hline & Stage II & 350 & 12 & 362 & & 353 & 28 & 381 & \\
\hline & Stage III + IV & 173 & 61 & 234 & & 174 & 90 & 264 & \\
\hline \multirow[t]{3}{*}{ AJCC T stage } & $\mathrm{T} 1$ & 656 & 17 & 673 & 0.000 & 660 & 56 & 716 & 0.000 \\
\hline & $\mathrm{T} 2$ & 371 & 20 & 391 & & 374 & 41 & 415 & \\
\hline & $\mathrm{T} 3+\mathrm{T} 4$ & 147 & 48 & 195 & & 148 & 72 & 220 & \\
\hline \multirow[t]{4}{*}{ AJCC $N$ stage } & NO & 1066 & 49 & 1115 & 0.000 & 1074 & 113 & 1187 & 0.000 \\
\hline & N1 & 32 & 18 & 50 & & 32 & 24 & 56 & \\
\hline & $\mathrm{N} 2+\mathrm{N} 3$ & 16 & 17 & 33 & & 16 & 24 & 40 & \\
\hline & NX & 60 & 1 & 61 & & 60 & 8 & 68 & \\
\hline \multirow[t]{2}{*}{ AJCC $M$ stage } & Mo & 1111 & 72 & 1183 & 0.000 & 1119 & 147 & 1266 & 0.000 \\
\hline & $\mathrm{M} 1+\mathrm{M} 2$ & 63 & 13 & 76 & & 63 & 22 & 85 & \\
\hline \multirow[t]{2}{*}{ Neck dissection } & No & 507 & 22 & 529 & 0.020 & 510 & 72 & 582 & 0.608 \\
\hline & Yes & 796 & 62 & 858 & & 801 & 104 & 905 & \\
\hline \multirow[t]{2}{*}{ Radiotherapy } & No & 1359 & 98 & 1457 & 0.000 & 1366 & 389 & 1755 & 0.002 \\
\hline & Yes & 624 & 122 & 746 & & 628 & 241 & 869 & \\
\hline \multirow[t]{2}{*}{ Chemotherapy } & No & 1966 & 203 & 2169 & 0.000 & 1977 & 610 & 2587 & 0.000 \\
\hline & Yes & 17 & 17 & 34 & & 17 & 20 & 37 & \\
\hline \multirow[t]{2}{*}{ Treatment } & Surgery & 1354 & 96 & 1450 & 0.000 & 1361 & 386 & 1747 & 0.010 \\
\hline & Surgery+RT & 611 & 107 & 718 & & 615 & 224 & 839 & \\
\hline
\end{tabular}




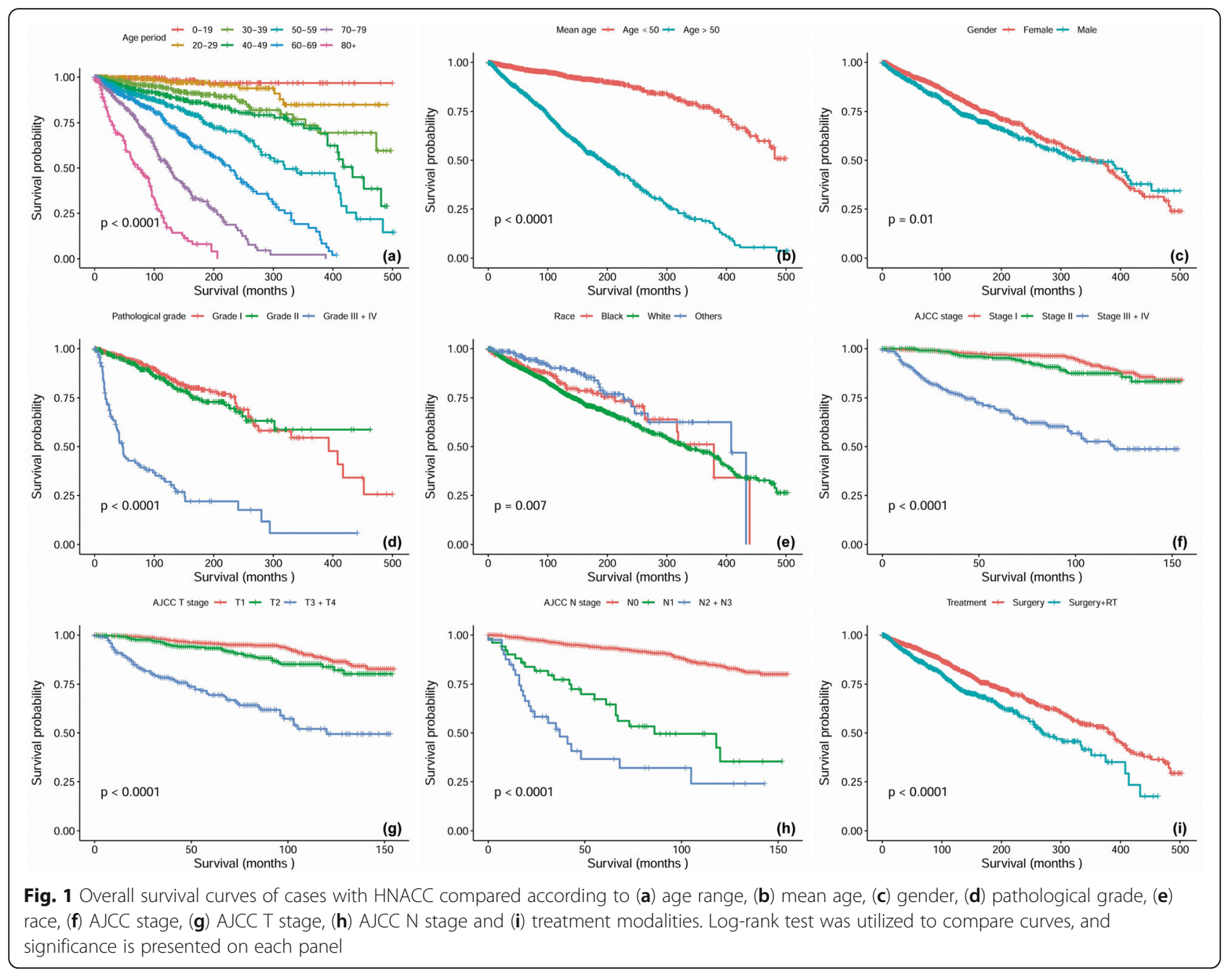

and 84.3 and $75.8 \%$, respectively, for patients who received surgery plus radiotherapy $(P<0.0001)$. In addition, statistically significant differences in DSS were found to be associated with age $(P<0.0001)$, race $(P=0.007)$, mean age $(P<0.0001)$, marital status at diagnosis $(P<0.0001)$, gender $(P=0.007)$, AJCC stage $(P<0.0001)$, AJCC T stage $(P<0.0001)$, AJCC N stage $(P<0.0001)$, AJCC $\mathrm{M}$ stage $(P<0.0001)$, neck dissection $(P=0.024)$ and pathological differentiation $(P<0.0001)$ (Fig. 2$)$.

Multivariate survival analysis was performed using the Cox proportional hazards regression model and the significant variables listed above. Surgical treatment was favourably associated with better DSS and OS [HR (95\% $\mathrm{CI})=0.13(0.03-0.6), P=0.0092$; HR $(95 \% \mathrm{CI})=0.23(0.07-$ $0.79), P=0.0203]$. Gender was the only demographic independent prognostic factor for both DSS and OS [Male vs female, HR $(95 \% \mathrm{CI})=3.3(1.51-7.22), P=0.0028$ for DSS; HR $(95 \% \mathrm{CI})=2.44(1.05-5.64), P=0.0376$ for OS]. Higher pathological grade was adversely associated with DSS and OS [Grade II HR $(95 \% \mathrm{CI})=4.03$ (1.04-15.7), $P=0.0444$; Grade III + IV, HR (95\% CI) $=35.64(10.9-125.94), P=$
0.0000 for DSS; Grade III + IV, HR $(95 \%$ CI $)=4.49(2.3-$ 8.77), $P=0.0000$ for OS, Grade I as reference]. Details of the multivariate Cox regression analysis are presented in Fig. 3.

\section{Discussion}

With the exception of case reports and small retrospective case series, no adequate data describing HNACC demographics are available $[4,9,10]$. In the current investigation, the gender incidence distribution showed a higher number of females than males, and there was a statistically significant predominance of HNACC in females $(P<0.001)$. HNACC could be found at any age, and the mean age at diagnosis was 50 years. Previous research on HNACC is based on single institutional experiences, and because of the small sample size, those studies are often not sufficiently powerful to find considerable differences in survival that are related to general demographic parameters [11-13]. In the survival analysis in our study, significant differences in DSS and OS were found to be related to age range, mean age, gender, race 


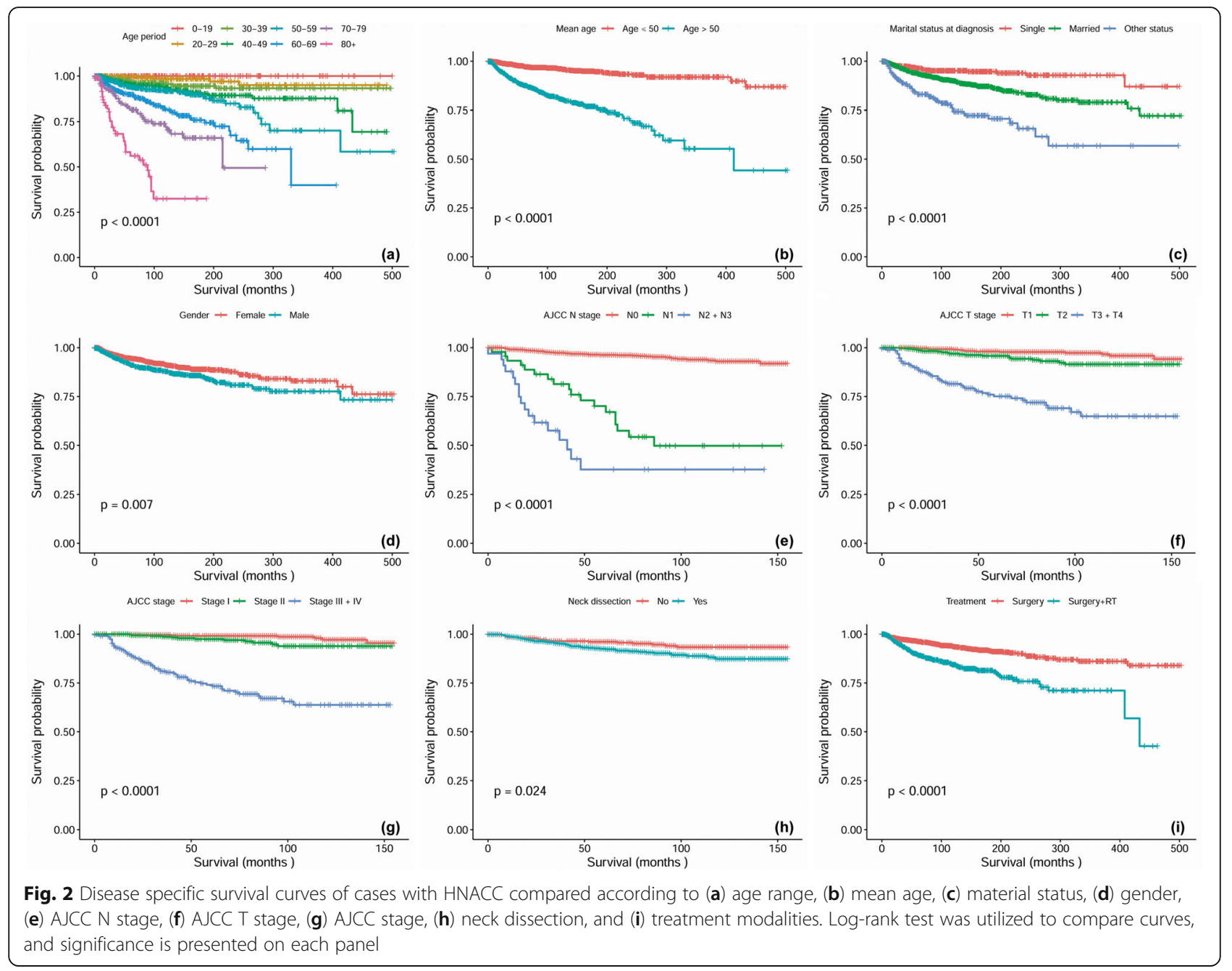

and marital status $(P<0.001)$. The most important findings regarding the demographics of HNACC are that gender and mean age are independent prognostic indicators for DSS and OS and that females under 50 years of age had more favourable prognosis than males over fifty.

TNM/AJCC staging plays an essential role in the planning of tumour treatment and in prognostic evaluation. The lymph node and distant metastasis rates of HNACC are low; the lymph node metastasis rate is less than $10 \%$, and the distant metastasis rate is approximately $5 \%$ [14]. In this circumstance, AJCC $\mathrm{T}$ stage plays a crucial role in prognosis evaluation; the larger the volume of the tumour is, the worse the prognosis is. In our results, AJCC T3 + T4 stage is an adverse independent OS prognostic indicator. There is a question of whether elective neck dissection should be performed in HNACC patients. In our DDS analysis, HNACC patients did not benefit from elective neck dissection. Patients with and without elective neck dissection showed no statistically significant differences in OS or in the survival analysis of the pathological grade III + IV subgroup and the AJCC
T3 + T4 stage subgroup. In view of the low frequency of metastases, routine elective treatment of the neck is not recommended. However, elective neck dissection should be considered in the treatment of large and high-grade tumours [15].

In previous articles, pathological grade was used as an important prognostic reference $[6,16,17]$. Consistent with earlier reports, our results indicate that pathological differentiation is the strongest prognostic indicator. Compared to well-differentiated Grade I HNACC cases, Grades II, III and IV are unfavourably associated with DSS and OS. The pathologic subtypes of ACC have been reported $[3,18]$. Unfortunately, the effects of these variants on prognosis could not be established because of the limited data. HNACC was mainly found in the parotid gland, and surgical resection was the primary treatment modality. Unlike the rest of the head and neck region, because of the presence of the facial nerve, the orientation of parotid gland ACC determines the type of surgery that is performed (Partial parotidectomy, superficial parotidectomy or total parotidectomy). The choice 


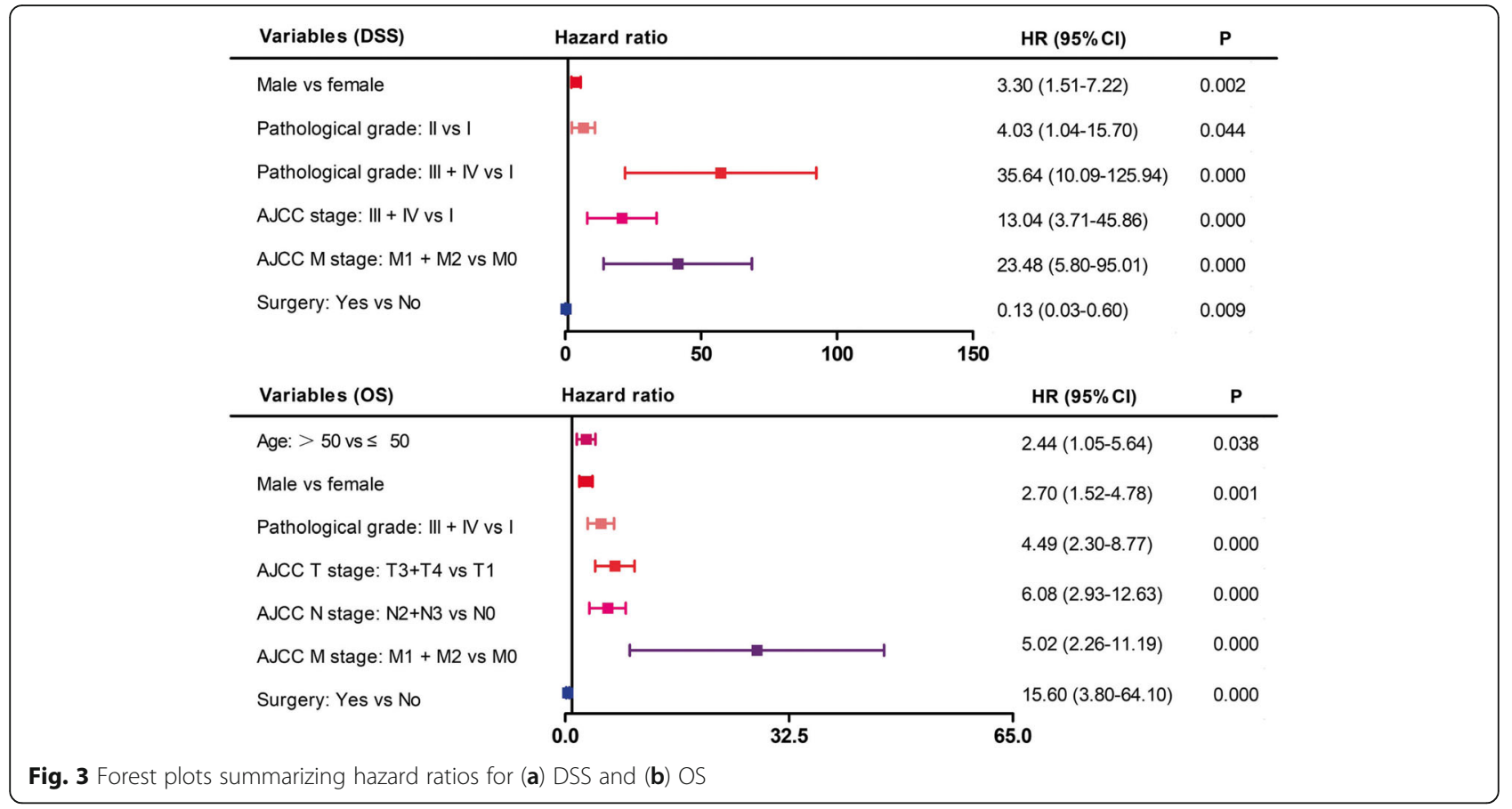

of surgical type has a huge impact on the prognosis of patients with parotid gland malignancies $[19,20]$. According to the distribution of sample size and site, we divided the study population into two groups: (a) parotid gland group and (b) beyond parotid gland group. The results of survival analysis show that there was no significant difference in the survival of these two groups. The SEER system does not provide detailed information about the location of parotid gland ACC or the type of surgery performed. Thus, we were unable to perform further analysis based on surgical type. In this cohort, 839 patients received radiotherapy; the prognosis of those patients was poor compared to that of patients who were treated with surgery alone. This result should be interpreted cautiously because in the clinical treatment of parotid gland ACC, radiotherapy is often implemented when adverse factors such as positive surgical margins or poor pathologic differentiation are present [21].

Several important limitations of this study are acknowledged. First, this SEER-based investigation was a retrospective analysis with some inherent bias. Some crucial data such as surgical type, surgical margins, and details of neck dissection could not be obtained, restricting further analysis. A geographic bias could not be totally avoided because of the nonuniform distribution of the SEER registries. Second, retrospective SEER-based analysis depends on accurate coding and consistent data collection among numerous sites, both of which can be imprecise. Third, due to the lack of complete data on adjuvant therapy, the role of radiotherapy and chemotherapy could not be well established. Finally, the retrospective nature of the study and the incompleteness of the clinicopathological data may weaken the strength of our conclusions.

\section{Conclusion}

In summary, despite the limitations of the incomplete data and of the study itself, to the best of our knowledge the present study is the first investigation to use a large study population and a long follow-up time to define the clinicopathologic characteristics and identify the prognostic indicators of ACC in the head and neck region. Three earlier reports described ACC cases reported in the National Cancer Database and the SEER database [2, 5, 14]. Although there is overlap among the study samples, the conclusions are complementary and enhance each other due to the different research intentions. Gender was the only demographic independent prognostic factor for both DSS and OS. With respect to treatment, surgical treatment was the only independent favourable prognostic factor for both DSS and OS. In addition, age, pathological differentiation, and TNM/AJCC stage were associated with DSS and OS.

\section{Abbreviations}

HNACC: Head and neck acinar cell carcinoma; SEER: Surveillance, Epidemiology, and End Results; OS: Overall survival; DSS: Disease-specific survival; HR: Hazard ratio; ACC: Acinar cell carcinoma; ICD-O-3: International Classification of Diseases for Oncology; AJCC: American Joint Committee on Cancer; SPSS: Statistical Package for the Social Sciences

\section{Acknowledgements}

We are grateful to American Journal Experts (https://www.aje.com, AJE, Durham, North Carolina, USA) for checking the English of the manuscript. 


\section{Authors' contributions}

ZY and AW contributed to the conception and design of the study; FY and LF performed the experiments, MW and ML collected and analyzed data; FY, $Y L$ and $H L$ wrote the manuscript; All authors reviewed and approved the final version of the manuscript.

\section{Funding}

None.

\section{Availability of data and materials}

Study data was publicly available in the SEER database.

\section{Ethics approval and consent to participate}

Not applicable.

\section{Consent for publication}

Not applicable.

\section{Competing interests}

The authors declare that they have no competing interest.

\section{Author details}

'Department of Oral \& Maxillofacial Surgery and Oral Biomedical Engineering Laboratory Shanghai Stomatological Hospital, Fudan University, 356 Beijing East Road, Shanghai 200001, People's Republic of China. ${ }^{2}$ Department of Preventive Medicine, School of Public Health, Shanghai Medical College, Fudan University, 138 Yi xue yuan Road, Shanghai 200001, People's Republic of China.

Received: 1 May 2020 Accepted: 12 June 2020

Published online: 08 July 2020

\section{References}

1. Bray F, Ferlay J, Soerjomataram I, Siegel RL, Torre LA, Jemal A. Global cancer statistics 2018: GLOBOCAN estimates of incidence and mortality worldwide for 36 cancers in 185 countries. CA Cancer J Clin. 2018:68(6):394-424.

2. Scherl C, Kato MG, Erkul E, Graboyes EM, Nguyen SA, Chi AC, Morgan PF, Day TA. Outcomes and prognostic factors for parotid acinic cell carcinoma: a National Cancer Database study of 2362 cases. Oral Oncol. 2018:82:53-60.

3. Al-Zaher N, Obeid A, Al-Salam S, Al-Kayyali BS. Acinic cell carcinoma of the salivary glands: a literature review. Hematol Oncol Stem Cell Ther. 2009;2(1): 259-64.

4. Suh SI, Seol HY, Kim TK, Lee NJ, Kim JH, Kim KA, Woo JS, Lee JH. Acinic cell carcinoma of the head and neck: radiologic-pathologic correlation. J Comput Assist Tomogr. 2005:29(1):121-6.

5. Biron VL, Lentsch EJ, Gerry DR, Bewley AF. Factors influencing survival in acinic cell carcinoma: a retrospective survival analysis of 2061 patients. Head Neck. 2015;37(6):870-7.

6. Schwarz S, Zenk J, Muller M, Ettl T, Wunsch PH, Hartmann A, Agaimy A. The many faces of acinic cell carcinomas of the salivary glands: a study of 40 cases relating histological and immunohistological subtypes to clinical parameters and prognosis. Histopathology. 2012;61(3):395-408.

7. Renehan A, Gleave EN, Hancock BD, Smith P, McGurk M. Long-term followup of over 1000 patients with salivary gland tumours treated in a single Centre. Br J Surg. 1996;83(12):1750-4.

8. Zenga J, Parikh AS, Emerick KS, Lin DT, Faquin WC, Deschler DG. Close margins and adjuvant radiotherapy in Acinic cell carcinoma of the parotid gland. JAMA Otolaryngol Head Neck Surg. 2018:144(11):1011-6.

9. Hoffman HT, Karnell LH, Robinson RA, Pinkston JA, Menck HR. National Cancer Data Base report on cancer of the head and neck: acinic cell carcinoma. Head Neck. 1999;21(4):297-309.

10. Omlie JE, Koutlas IG. Acinic cell carcinoma of minor salivary glands: a clinicopathologic study of 21 cases. J Oral Maxillofac Surg. 2010:68(9):2053-7.

11. Grasl S, Janik S, Grasl MC, Pammer J, Formanek M, Weinreb I, Perez-Ordonez B, Hope A, Hosni A, de Almeida JR, et al. Nodal metastases in Acinic cell carcinoma of the parotid gland. J Clin Med. 2019;8(9):1315.

12. Cellich PP, Nayyar R, Wong E. Acinic cell carcinoma of the parotid gland in pregnancy: an approach to cancer in pregnancy. BMJ Case Rep. 2018;2018.

13. Thompson LD, Aslam MN, Stall JN, Udager AM, Chiosea S, McHugh JB. Clinicopathologic and Immunophenotypic characterization of 25 cases of
Acinic cell carcinoma with high-grade transformation. Head Neck Pathol. 2016:10(2):152-60

14. Patel NR, Sanghvi S, Khan MN, Husain Q, Baredes S, Eloy JA. Demographic trends and disease-specific survival in salivary acinic cell carcinoma: an analysis of 1129 cases. Laryngoscope. 2014;124(1):172-8.

15. Armstrong JG, Harrison LB, Thaler HT, Friedlander-Klar H, Fass DE, Zelefsky MJ, Shah JP, Strong EW, Spiro RH. The indications for elective treatment of the neck in cancer of the major salivary glands. Cancer. 1992;69(3):615-9.

16. Wang $Y L$, Zhu $Y X$, Chen $T Z$, Wang $Y$, Sun GH, Zhang L, Huang $C P$, Wang $Z Y$, Shen Q, Li DS, et al. Clinicopathologic study of 1176 salivary gland tumors in a Chinese population: experience of one cancer center 1997-2007. Acta Otolaryngol. 2012;132(8):879-86.

17. Bjorndal K, Krogdahl A, Therkildsen MH, Overgaard J, Johansen J, Kristensen $\mathrm{CA}$, Homoe P, Sorensen $\mathrm{CH}$, Andersen E, Bundgaard T, et al. Salivary gland carcinoma in Denmark 1990-2005: A national study of incidence, site and histology. Results of the Danish head and neck Cancer group (DAHANCA). Oral Oncol. 2011:47(7):677-82.

18. Lewis JE, Olsen KD, Weiland LH. Acinic cell carcinoma. Clinicopathologic review. Cancer. 1991;67(1):172-9.

19. Roh JL, Kim HS, Park Cl. Randomized clinical trial comparing partial parotidectomy versus superficial or total parotidectomy. Br J Surg. 2007; 94(9):1081-7.

20. Li C, Xu Y, Zhang C, Sun C, Chen Y, Zhao H, Li G, Fan J, Lei D. Modified partial superficial parotidectomy versus conventional superficial parotidectomy improves treatment of pleomorphic adenoma of the parotid gland. Am J Surg. 2014:208(1):112-8.

21. Lewis AG, Tong T, Maghami E. Diagnosis and Management of Malignant Salivary Gland Tumors of the parotid gland. Otolaryngol Clin N Am. 2016; 49(2):343-80.

\section{Publisher's Note}

Springer Nature remains neutral with regard to jurisdictional claims in published maps and institutional affiliations.

Ready to submit your research? Choose BMC and benefit from:

- fast, convenient online submission

- thorough peer review by experienced researchers in your field

- rapid publication on acceptance

- support for research data, including large and complex data types

- gold Open Access which fosters wider collaboration and increased citations

- maximum visibility for your research: over $100 \mathrm{M}$ website views per year

At $\mathrm{BMC}$, research is always in progress.

Learn more biomedcentral.com/submission 